\title{
Transanal Minimally Invasive Surgery After Chemoradiotherapy: Widening Scope of Indications for Local Excision
}

\author{
Min Jung Kim, Jae Hwan Oh \\ Center for Colorectal Cancer, Research Institute and Hospital, National Cancer Center, Goyang, Korea
}

\section{See Article on Page 52-56}

The surgical approach for treating patients with rectal cancer has evolved from the perineal resection to sphincter-saving surgery so as to decrease local recurrence and to preserve organs. Along with surgical advances such as the total mesorectal excision (TME), the introduction of chemoradiotherapy (CRT) has significantly lowered the local recurrence rate from $15 \%-20 \%$ to $4 \%-5 \%$ [1]. However, the TME with CRT is associated with a mortality rate of $1 \%-4 \%$ and a morbidity, including bowel and urogenital dysfunction, rate of $\sim 40 \%$. The postoperative morbidity associated with the TME and the good oncologic outcomes in downstaged patients after CRT have raised questions regarding the utility of a mesorectal resection.

Local excision after CRT can be posited as an option for good responders with locally advanced rectal cancers so as to preserve the rectum and to achieve a local recurrence comparable to that of the TME. A sequential 2-stage phase II study was performed with 63 patients, and the 3-year disease-free survival was 91\% [2]. According to the GRECCAR 2 randomized trial for patients with clinical stage II to III rectal cancer, of the good clinical responders who underwent long-course CRT, $46 \%$ had a chance of rectal preservation (presented in American Society for Radiation Oncology 2014). In Lee et al. [3]'s study, 2 of the 35 patients who underwent transanal minimally invasive surgery (TAMIS) had local recurrences without distant metastasis, and complete salvage could be achieved for one patient.

TAMIS, a technique developed in 2009 [4], has several advan-

Correspondence to: Jae Hwan Oh, M.D.

Center for Colorectal Cancer, Research Institute and Hospital, National

Cancer Center, 323 Ilsan-ro, Ilsandong-gu, Goyang 10408, Korea

Tel: +82-31-920-1505, Fax: +82-31-920-2798, E-mail: jayoh@ncc.re.kr

(C) 2017 The Korean Society of Coloproctology

This is an open-access article distributed under the terms of the Creative Commons Attribution NonCommercial License (http://creativecommons.org/licenses/by-nc/4.0) which permits unrestricted noncommercial use, distribution, and reproduction in any medium, provided the original work is properly cited. tages over conventional transanal local excision or transanal endoscopic microsurgery (TEM). The main benefits are a wide and clear view of the tumor, a short setup time, use of familiar laparoscopic instruments, a wide range of motion, a freely movable camera, and applicability to the proximally located rectal tumors. Moreover, TAMIS is a cost-effective alternative to the TEM [4]. Lee et al. [3] attempted to apply this relatively new technique for local excision in good responders with locally advanced rectal cancer after CRT, a course of treatment that has been highly debated recently. While concerns regarding the oncologic outcomes of local excision after CRT are still present, this study demonstrates the technical and oncological feasibility of TAMIS for patients eligible for local excision, even after CRT. Further investigations should be conducted to select patients who could benefit from TAMIS after CRT.

\section{CONFLICT OF INTEREST}

No potential conflict of interest relevant to this article was reported.

\section{REFERENCES}

1. Fleshman JW, Smallwood N. Current concepts in rectal cancer. Clin Colon Rectal Surg 2015;28:5-11.

2. Pucciarelli S, De Paoli A, Guerrieri M, La Torre G, Maretto I, De Marchi F, et al. Local excision after preoperative chemoradiotherapy for rectal cancer: results of a multicenter phase II clinical trial. Dis Colon Rectum 2013;56:1349-56.

3. Lee BC, Oh S, Lim SB, Yu CS, Kim JC. Transanal minimally-invasive surgery for treating patients with regressed rectal cancer after preoperative chemoradiotherapy. Ann Coloproctol 2017;33:52-6.

4. Atallah S, Albert M, Larach S. Transanal minimally invasive surgery: a giant leap forward. Surg Endosc 2010;24:2200-5. 